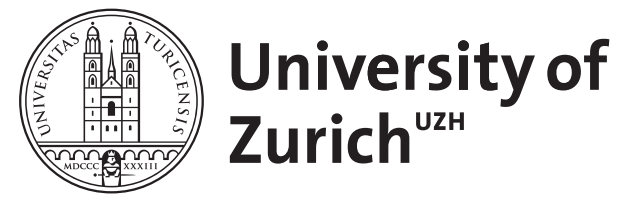

Zurich Open Repository and Archive

University of Zurich

University Library

Strickhofstrasse 39

CH-8057 Zurich

www.zora.uzh.ch

Year: 1973

Transport of carbon in nonisothermal low pressure nitrogen plasma

Vepřek, S

DOI: https://doi.org/10.1524/zpch.1973.86.1_2.095

Posted at the Zurich Open Repository and Archive, University of Zurich

ZORA URL: https://doi.org/10.5167/uzh-154344

Journal Article

Published Version

Originally published at:

Vepřek, S (1973). Transport of carbon in nonisothermal low pressure nitrogen plasma. Zeitschrift für Physikalische Chemie, 86(12) : $95-107$.

DOI: https://doi.org/10.1524/zpch.1973.86.1_2.095 


\title{
Transport of Carbon in Nonisothermal Low Pressure Nitrogen Plasma
}

\author{
By \\ S. VEP ̌̌EK \\ Institute of Inorganic Chemistry, University of Zürich \\ Rämistrasse 76, Zürich, Switzerland
}

With 3 figures

(Received January 29, 1973)

\section{Zusammenfassung}

Kohlenstoff konnte mit Stickstoff in einem nichtisothermen Niederdruckplasma einer Hochfrequenzentladung transportiert werden. Der Transport erfolgte in Richtung abnehmender Plasmaenergie bei Translationstemperaturen von etwa $1000^{\circ} \mathrm{C}$. Eine Diskussion der Elementarprozesse und ein Vergleich mit theoretischen Vorstellungen liefert tiefere Einblicke in die Vorgänge bei der chemischen Verdampfung und Abscheidung fester Stoffe unter den Bedingungen eines nicht isothermen Plasmas.

\section{Abstract}

Carbon has been transported with nitrogen in a nonisothermal low-pressure plasma of a highfrequency discharge. The transport proceeds in the direction of decreasing plasma energy at a translational temperature of about $1000^{\circ} \mathrm{C}$. A discussion of elementary processes and a comparison with theory leads to a deeper insight into the processes of chemical evaporation and deposition of solids under nonisothermal plasma conditions.

\section{Introduction}

Chemical transport reactions ${ }^{1}$ are well known methods for the growth of crystals and thin films from the gas phase. The use of nonisothermal plasma* makes transport possible also in systems in

* For further information about this kind of plasma see ${ }^{2}$ and references mentioned there.

1 H. SchäfER, Chemische Transportreaktionen, Verlag Chemie, Weinheim/ Bergstr. 1962, Academic Press, New York 1964. 
which it is otherwise hindered kinetically or thermodynamically (without a plasma). In an earlier paper ${ }^{2}$ we have demonstrated the kinetic effect of a weak discharge by the transport of carbon according to the Boudouard's reaction and the thermodynamic effect of an intense highfrequency low-pressure discharge in systems which are strongly exothermic without the plasma (such as $\mathrm{TiN} / \mathrm{Cl}_{2}, \mathrm{AlN} / \mathrm{Cl}_{2}{ }^{3}$ and $\mathrm{C} / \mathrm{H}_{2}, \mathrm{C} / \mathrm{O}_{2}{ }^{2}$ ). In this paper we shall show how a nonisothermal plasma having a high energy content can shift chemical equilibrium of a strongly endothermic reaction in such a way that chemical transport becomes possible at a temperature of the solid at which it would be quite impossible under thermodynamical equilibrium conditions. The system carbon-nitrogen seems to be very suitable for this purpose in view of its simplicity, sufficient knowledge of the elementary processes involved and the possibility of a comparison with transport in other systems like carbon-hydrogen and carbonoxygen $^{2}$.

Several results of this study have been already mentioned in our previous papers ${ }^{2,4}$. In this article, a short description of the experiments along with a discussion of elementary processes in the system under consideration will be given.

The carbon-nitrogen system has been studied under plasma conditons by a number of authors ${ }^{5-18}$. Because of insufficient information

2 S. VEP̌̌Ek, Second Int. Conf. Vapour Growth \& Epitaxy, Jerusalem 1972, J. Cryst. Growth 17 (1972) 101.

3 S. Vepřek, C. Brendex and H. Schäfer, J. Cryst. Growth 9 (1971) 266.

4 S. Vepřek, J. chem. Physics 57 (1972) 952.

5 M. Morren, Compt. Rend. (Paris) 48 (1859) 342.

6 Modern Aspects of Graphite Technology, ed. L. Blackman, Academic Press, London 1970.

7 F. K. McTaggart, Plasma Chemistry in Electrical Discharges, Elsevier, Amsterdam 1967.

8 A. Wright and C. Winkler, Active Nitrogen, Academic Press, New York 1968.

9 R. Baddour and R. Timmins, The Application of Plasmas to Chemical Processing, M.I.T. Press, Cambridge (Massachusetts) 1967.

10 G. Glocker and S. Lind, The Electrochemistry of Gases and other Dielectrics, J. Wiley, New York 1939.

11 C. Fink and D. Wroughton, Trans, electrochem. Soc. 88 (1945) 25.

12 H. Goldstein, J. physic. Chem. 68 (1964) 39.

13 H. v. WARtenberg, Z. anorg. Chem. 52 (1907) 299.

14 C. Stokes and W. KNIPE, Ind. Engng. Chem. 52 (1960) 287.

15 T. Wallis, Ann. Chem. 345 (1906) 353.

16 E. Briner and J. Deshusses, Helv. chim. Acta 13 (1930) 629. 
about the experimental conditions (basic plasma parameters) a comparison of different experiments is difficult or quite impossible in most cases. There are two important kinds of experiments which have to be distinguished: Experiments in a high temperature plasma (arc-discharge, plasma jet) and in a "cold" plasma (glow- and highfrequency low-pressure discharge). The present paper deals with a nonisothermal low-pressure plasma of an intense highfrequency discharge.

It will be shown, that, when the inner energy of the plasma reaches a value of about $100 \mathrm{kcal} / \mathrm{mole}$ and the translational temperature lies close to $1000^{\circ} \mathrm{C}$, the transport of carbon takes place in the direction of lower plasma energy, $\varepsilon_{2} \rightarrow \varepsilon_{1}$ (see sect. 3). Under these conditions, the energy in the translational (and also rotational and vibrational) degrees of freedom of heavy particles (about $5 \mathrm{kcal} / \mathrm{mole}$ ) is much lower than the energy in the electronical ones (about $100 \mathrm{kcal} / \mathrm{mole}$ ). Therefore, the usual chemical thermodynamics as well as the linear irreversible thermodynamics are not valid here. Also the general thermodynamic theory of stability cannot be used in its present form ${ }^{19}$ as the assumption of local equilibrium is violated already in individual molecules. Only a simple statistical model of chemical reaction under nonisothermal plasma conditions ${ }^{4}$ can be used for prediction of chemical transport today.

\section{Experiments}

The experimental arrangement is schematically shown in Fig.1. The highfrequency discharge takes place between the outer electrodes 2 and $2^{\prime}$ in a silica tube 1 (inner diameter $R=37 \mathrm{~mm}$ ). The highfrequency output of generator 3 (type Philips PH 1202/00) may be adjusted between 0 and $1.2 \mathrm{~kW}$ at the frequency of $80 \mathrm{MHz}$. The h.f. current is measured by a special amperemeter 14 . The gas flow and the total pressure in the discharge tube are adjustable by means of needle valve 5 , vacuum valve 6 and rotary oil pump 4 . The pressure in tube 1 is measured by McLeod- and oil-manometers 7 . Cold trap 8 prevents a penetration of oil- and mercury-vapour into the plasma. Pure nitrogen with a total oxygen- and water-traces below $0.5 \mathrm{ppm}$ has been used in all experiments.

17 M. Berthelot, Compt. Rend. (Paris) 95 (1882) 955; 145 (1907) 354.

18 K. Peters, Naturwissenschaften 19 (1931) 402.

19 P. Glansdorf and I. Prigogine, Thermodynamic Theory of Structure, Stability and Fluctuations, Wiley, London 1971. 


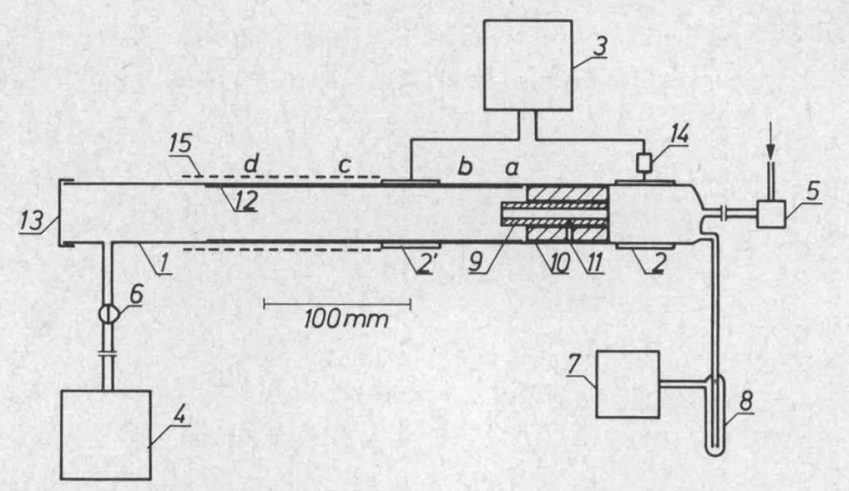

Fig. 1. Experimental arrangement for the transport of carbon in nitrogen plasma. Description see text. The length scale to be applied only for the discharge tube

Spectral pure graphite tube 9 (Ringsdorff Company, diameters $15 / 8 \mathrm{~mm}$ ) is placed in nickel inlay 10 . The temperature of the graphite surface inside tube 9 is measured by an optical pyrometer through orifice 11. Because of the non-equilibrium radiation of plasma under these conditions, direct measurement of surface temperature is not possible in the active discharge. Comparable measurements of the temperature of the graphite surface inside tube 9 and in borehole 11 after switching off the discharge show that the difference between both values are smaller than $40^{\circ}$ at a temperature of about $900^{\circ} \mathrm{C}$.

\section{Experiment No. I}

50-100 $\mathrm{mg}$ carbon are transported per hour from the inside of graphite tube 9 into the silica inlay 12 at a total pressure of 1 Torr, a gas flow of about 100 Torr $\mathrm{cm}^{3} / \mathrm{sec}$ and a h.f. current between 2 and $4 \mathrm{~A}$. The temperature of the graphite surface reaches a value between 950 and $1000^{\circ} \mathrm{C}$ in the tube 9 and about $800^{\circ} \mathrm{C}$ in zone $a$ and $b$ of silica inlay 12. Discharge tube 1 is isolated with asbestos (heat-isolation) 15 on the left of electrode $2^{\prime}$.

Fig. 2 shows the carbon deposited in zone $b$ of inlay 12 (cf. Fig.1). There is large amount of soot deposited in zone $a$ and a small amount in zone $c$ on the left of the electrode $2^{\prime}$. No paracyanogen $(C N)_{x}$ has been found in the carbon deposited under these conditions (IR- and mass spectrometry).

The amount of transported carbon increases with increasing h.f. current from 2-4 A. Both the inner energy as well as the translational 


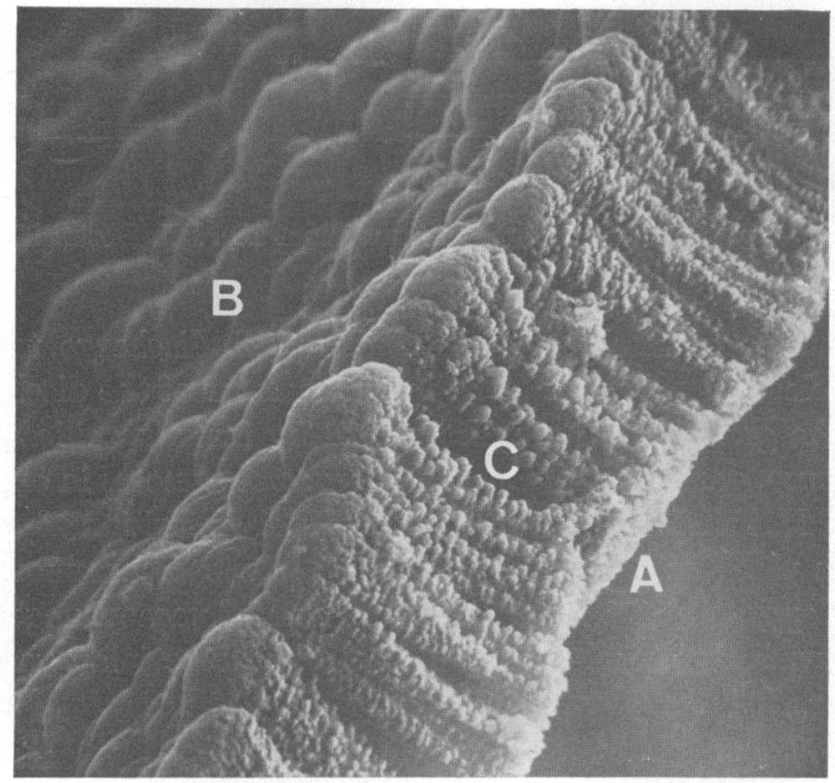

Fig. 2. Carbon deposited in the zone $b$ of Fig. 1. A) surface in contact with the substrate (silica), B) growth surface, C) a cut through the layer. Scanning electron microscope (stereoscan) picture; $1500 \times$

temperature of the plasma increase simultaneously ${ }^{3,20}$. The variations of the temperature of the carbon surface in tube 9 are smaller than the accuracy of its measurements.

\section{Experiment No. II}

The graphite tube 9 and the nickel inlay 10 are shifted to electrode $2^{\prime}$ and heat isolation 15 is removed (cf. Fig. 1). The distance between electrode $2^{\prime}$ and nickel inlay 10 is about $5 \mathrm{~mm}$. The total pressure, gas flow and h.f. current are kept at the same value as before. There is a mingling of carbon (soot) and paracyanogen deposited on the left of electrode $2^{\prime}$. The material deposited in zone $c$ contains more paracyanogen than material of zone $d$ (IR- and mass spectrometry, habitus).

\section{Experiment No. III}

The arrangement of the discharge tube is shown in Fig. 3. Graphite $\operatorname{rod} 17$ (diameter $13 \mathrm{~mm}$, length $35 \mathrm{~mm}$ ) is fixed with silica stick 16

$20 \mathrm{~S}$. Vepřek, Dissertation, University of Zürich, 1972. 


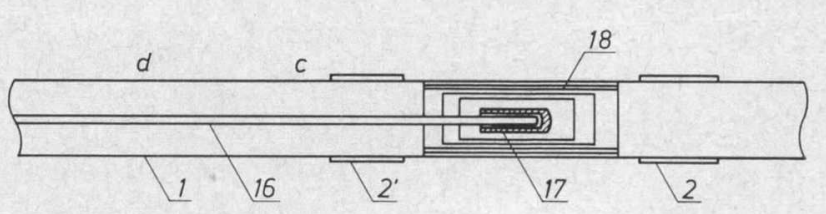

Fig. 3. Experimental arrangement for experiment No. III. Description see text

in the middle of discharge tube 1. The h.f. discharge takes place between electrodes 2 and $2^{\prime}$. The inner diameter of the discharge tube around the graphite rod may be varied by inserting silica tubes 18 . The pressure, gas flow and h.f. current are the same as in experiments No. I and II. Neither transport of carbon, nor deposition of paracyanogen takes place without inlay 18 . If the inlays 18 are mounted into tube 1, deposition of carbon in zone $d$ and of paracyanogen in zone $c$ is observed. The smallest inner diameter of the inlay used around graphite rod 17 was $25 \mathrm{~mm}$.

\section{Experiment No. IV}

The graphite rod from the previous experiment is now fixed in the middle of a discharge tube with the diameter of $100 \mathrm{~mm}$. The temperature of graphite is measured with a gas thermometer. A WredeHarteck gauge (cf. e.g. ${ }^{7}$, p. 76) is used for measurement of the degree of nitrogen dissociation in the discharge. At the total pressure of 1.35 Torr and h.f. current of $6.3 \mathrm{~A}$, a graphite temperature of $590^{\circ} \mathrm{C}$ and a degree of dissociation of about $50 \%$ are found ${ }^{20}$. The temperature of the tube wall lies between 200 and $300^{\circ} \mathrm{C}$.

Under these conditions, about $1.5 \mathrm{mg}$ carbon per hour reacts with nitrogen, and paracyanogen is deposited on the wall of the discharge tube between the electrodes. No deposition of carbon can be observed in this experiment. The reaction rate increases with increasing h.f. current. At the same time also the temperature of graphite increases (e.g. up to $630^{\circ} \mathrm{C}$ at the h.f. current of $10 \mathrm{~A}$ ). The reaction is not observable when the temperature of graphite is too low (e.g. $300^{\circ} \mathrm{C}$ ) although a degree of dissociation higher than $20 \%$ is found ${ }^{20}$.

In all experiments careful efforts have been made to exclude traces of humidity from the reacting system. No $H C N$ has been detected in carbon and paracyanogen deposited in these experiments (IR- and mass spectrometry). 


\section{Discussion}

A comparison of experiments No. I, III and IV shows that both high energy content and high translational temperature (resp. the temperature of carbon in the starting zone) are necessary for the formation of cyanogen. Experiment No. II indicates that the "carbon carrying species" during the transport is the cyanogen monomer CN (cf. also ${ }^{21}$ ). The largest part of the inner energy of the plasma corresponds to the dissociation energy when the degree of dissociation is higher than about $50 \%$. Thus, the degree of dissociation may be used as a rough measure of the plasma energy under these conditions. The dissociation of nitrogen increases with an increasing ratio h.f. current vs. tube diameter, $I / R^{3,20}$. Because of the continuity of the electric current, the $I / R$ ratio is larger in graphite tube 9 (see Fig. 1) than in silica inlay 12. Carbon is then transported in the direction of lower plasma energy $\varepsilon_{2} \rightarrow \varepsilon_{1}$.

We shall now discuss the elementary processes occuring in the plasma. The reaction of carbon with molecular nitrogen

$$
C_{s}+\frac{1}{2} N_{2, g} \rightleftharpoons C H_{g}
$$

is strongly endothermic $\left(\Delta H_{298}^{\circ}=109 \mathrm{kcal} / \mathrm{mole}^{22}\right)$ and a significant concentration of cyanogen arises under thermodynamical equilibrium condition in the gas phase only at very high temperature. It has been suggested that the rate determining step in the carbon-nitrogen reaction is the adsorption of $N_{2}$ on two adjacent carbon atoms $\left({ }^{23}\right.$, p. 194). Because of the high dissociation energy of the nitrogen molecule, the reaction proceeds with a significant rate only above $2000^{\circ} \mathrm{C}$. There is also some evidence that the $C H$ molecule leaving the carbon surface is electronically excited $\left(B^{2} \sum \text { state }\right)^{24}$.

The transport of carbon proceeds in the discharge according to the reaction (2).

$$
C_{s}+1 / x N_{x, g}^{*} \rightleftharpoons C H_{g} .
$$

Here, $N_{x, g}^{*}$ stands for nitrogen in a plasma state with a high energy content. The necessary energies of the $N_{x, g}^{*}$ species participating in

21 C. Haggart and C. Winkrer, Canad. J. Chem. 38 (1960) 329.

22 JANAF Thermochemical Tables, US Nat. Bur. Stand., second edition, NSRDS-NBS 37 (1971).

${ }^{23}$ Gmelins Handbuch der anorg. Chemie, Bd. 14, D 1, Verlag Chemie, Weinheim/Bergstr. 1971.

${ }^{24}$ A. Floy and R. King, J. Opt. Soc. Amer. 45 (1955) 249, 252. 
reaction (2) have to be equal to or higher than $\Delta H^{\circ}$ of reaction (1). Moreover, for the chemical equilibrium of reaction (2) to be established, the reaction has to be fast.

We will now discuss the nature of the particles participating in reaction (2). Consider starting from the plasma state with a low concentration of cyanogen which does not disturb the composition of discharge in pure nitrogen significantly. This low concentration can originate either from a low value of the plasma energy or from a low translational temperature (see later).

Of the molecular species arising in the nitrogen low-pressure discharge with a significant concentration there are predominantly molecules in the ground $\left(X^{1} \Sigma_{g}^{+}\right)$and the metastable $\left(A^{3} \Sigma_{u}^{+}\right)$states. The ground state can be vibrationally excited to several $\mathrm{eV}$, but the higher levels have short relaxation times. The relatively high concentration of vibrational excited molecules in the nitrogen afterglow of the microwave discharge (about $30 \%{ }^{25}$ )corresponds predominantly to the first vibrational level $\left(X^{1} \Sigma_{g}^{+}, v=1{ }^{26}\right)$ having a mean life time of about $50 \mathrm{msec}$ at 1 Torr under the experimental conditions. The energy released by the deactivation of the vibrationally excited species was found to be only about $2 \mathrm{kcal} / \mathrm{mole} 25$. Highfrequency discharges produce quite small amounts of vibrational excited molecules and also the vibrational deexcitation may be expected to be faster in active discharge than in the afterglow (e.g. the deactivation of vibrationally excited $\mathrm{O}_{2}$ in collisions with atoms can be two orders of magnitude faster than in collisions with molecules ${ }^{27}$ ). Then, the ground electronic state of molecules can be assumed not to participate in the reaction (2).

The metastable $N_{2}\left(A^{3} \Sigma_{u}^{+}\right)$can arise in relatively high concentrations in the plasma, but its energy $(6.17 \mathrm{eV}$ for $v=0)$ is not sufficient for the formation of $C N$ molecules. This process may perhaps be feasible through some surface reaction under participation of more of such species, but because of a short life time of the $\left(A^{3} \Sigma_{u}{ }^{+}\right)$state (radiative life time between $10^{-4}$ and $10^{-2} \mathrm{sec}^{8}$, pp. 96-97) it seems to be improbable. The other molecular species have very short radiative life times $\left(10^{-6}-10^{-8} \mathrm{sec}\right)$ and will not play any significant role.

25 F. Kaufman and J. Kelso, J. chem. Physics 28 (1958) 510.

${ }^{26}$ K. Dressler, J. chem. Physics 30 (1959) 1621.

27 R. Gordon, W. Klemperer and J. Y. Steinfeld, in Annual Review of Phys. Chem., Vol. 19, ed. H. Eyring, G. Banta Comp. Inc., Palo Alto 1968. 
Generally, it seems likely that any molecular excited species will be deactivated at the surface of a solid rather than undergo a chemical reaction with it.

The situation becomes quite different if atomic species participate in reaction (2). There are the ground state $N\left({ }^{4} S\right)$ and the metastables $N\left({ }^{2} D\right)$ and $N\left({ }^{2} P\right)$ which have long radiative life times of 26 hours and 12 seconds respectively $\left({ }^{8}\right.$, p. $\left.82-83\right)$. The deactivation of the metastable species proceeds predominantly through collisions with the wall or other species. Reaction (2) is weakly exothermic $\left(\Delta H_{298}^{\circ}=\right.$ $-4 \mathrm{kcal} / \mathrm{mole}^{22}$ ), with atomic nitrogen in the ground state and it becomes much more exothermic when the metastables participate. In the active discharge in nitrogen a very high degree of dissociation can be obtained at the pressure of 1 Torr (cf. ${ }^{3,20}$ ). At a lower degree of dissociation of nitrogen, the ground state $N\left({ }^{4} S\right)$ will predominate but the concentration of metastables [mainly $N\left({ }^{2} D\right)$ ] becomes significant at a degree of dissociation close to one [e.g. only $1 / 500$ of nitrogen atoms are metastable in the afterglow, but about $5-20 \% N\left({ }^{4} S\right)$ atoms occur in the discharge in a mixture of nitrogen with inert gas $^{8}$, p. 82]

At 1 Torr, the atoms disappear either by recombination on the wall and to a lower extent in the gas phase or by reaction (2). The value of the recombination coefficient of nitrogen on quartz is of the order of $10^{-3}-10^{-4}\left({ }^{8}\right.$, p. 170) and leads to a mean life time of the atoms of the order of $10^{-1}-10^{-2}$ sec. The recombination coefficient changes relatively little with temperature (activation energy between 0 and $2 \mathrm{kcal} / \mathrm{mole}$ ). We do not know any value for the recombination coefficient of nitrogen on graphite. Measurements of surface temperatures of different solids in nitrogen plasma indicate that the recombination of nitrogen atoms on the carbon surface is slower than on quartz. Especially at higher temperatures $\left(900^{\circ} \mathrm{K}\right)$ the catalytic heating of the carbon becomes lower and it approaches the value of a quartz surface "poisoned" with $\mathrm{HPO}_{3}{ }^{20}$.

The reaction rate of atomic nitrogen with graphite can be calculated from the values of the activation energy and entropy of about $18.5 \mathrm{kcal} / \mathrm{mole}$ and $-2.7 \mathrm{cal} / \mathrm{mole}$ deg respectively as measured by GoLDSTEIN ${ }^{12}$. These data give the probability of reaction $C_{s}+N_{g} \rightarrow C N_{g}$ for a nitrogen atom striking the carbon surface of about $2.7 \cdot 10^{-5}$ at $890^{\circ} \mathrm{K}$ and $1.8 \cdot 10^{-4}$ at $1275^{\circ} \mathrm{K}$, which seems to be very low for setting up the chemical equilibrium of the reaction (2). However, two factors have to be accounted for when the reaction proceeds in an 
active discharge*: First, the excited atoms may be responsible for the higher reaction rate in comparison with the reaction outside the plasma. Second, for the setting up of the chemical equilibrium of reaction (2) the ratio of the reaction probability to the recombination coefficient is more decisive than the absolute values are. The surface recombination takes place between an atom striking the surface and another one being adsorbed there (e.g. ${ }^{28,30}$ ). Thus, if the desorption of $C N$-radicals from the surface increases, the surface recombination of atoms will decrease. (A similar effect has been observed also by recombination of nitrogen atoms on a nickel surface at a temperature of about $1000^{\circ} \mathrm{C}^{31}$ ).

The measurements of the surface temperature (see above) and the comparison of the amount of transported carbon with the value calculated from GoLDsteIn's data (see 4, Tab.1) show that the reaction of atoms with carbon is faster than its surface recombination at a high temperature.

What is the rate determining step in the reaction $C_{s}+N_{g} \rightarrow C N_{g}$ ? At a carbon temperature up to $800^{\circ} \mathrm{C}$ this reaction proceeds slowly (cf. 4 1) in pure nitrogen, but the formation of $H C N$ proceeds quickly when a small amount of hydrogen is added ${ }^{32,33}$. The decrease of the catalytic efficiency of the carbon surface for the nitrogen recombination at higher temperature in the plasma suggests that the nitrogen atoms are strongly chemisorbed on the surface and the slowest step is the desorption of the $C N$ species from the surface.

This molecule can leave the surface by being electronically excited into the $\left(A^{2} \Pi\right)$ or $\left(B^{2} \Sigma^{+}\right)$states (cf. ${ }^{24}$ and $\left.{ }^{34}\right)$, but in view of their short radiative life times $\left(3.5 \cdot 10^{-6} \mathrm{sec}\right.$ and $8.5 \cdot 10^{-8} \mathrm{sec}$ respective$\left.{ }^{1 y^{23}}\right)$, the ground state $\left(X^{2} \Sigma^{+}\right)$of $C N$ will predominate in the gas

* Goldsteins measurement has been done under conditions hot solid-cold gas. Due to the thermal accomodation of the gas on the hot surface, the reaction rate is lower under such conditions than in our case of equal tempera. tures.

${ }^{28}$ Handbuch der Katalyse, Vol. IV, ed. G. SchwaB, Wien 1943.

${ }^{29}$ Chemical Reactions in Electrical Discharges, ed. B. Blaustein, Adv. Chem. Ser. 80, Amer. Chem. Soc., Washington D.C. 1969.

30 F. KaUfmaN, in ${ }^{29}$, p. $29-47$.

31 N. Buben and A. Schechter, Acta physicochim. URSS 10 (1939) 371.

32 W. Zinman, J. Amer. chem. Soc. 82 (1960) 1262.

33 M. Coulon and L. Bonnetain, Compt. Rend. C 269 (1969) 1469.

34 M. Savadatti and H. Broida, J. chem. Physics 45 (1966) 2390. 
phase. Also a very fast collisional quenching of these states has to be accounted for (ef. quenching of $B^{2} \Sigma^{+35}$ ).

The other species occuring in the plasma, e.g. short lived high excited atoms and molecules as well as ions, can influence the overall reaction rate, but they do not contribute to the energy balance of the system significantly and can be neglected in this consideration.

The $C N$ molecule in the gas phase can either decompose or undergo collisions with other $C N$ species and polymerize. These processes will be considered now. The decomposition can proceed either by electron impact or by collisions with other heavy species or on the wall. A simple assessment shows that in the plasma under consideration, the mean life time of the $C N$ molecule being decomposed only by electron excitation is $10^{-2}-10^{-3}$ sec or longer 4 . (The dissociation energy of $C N$ molecule is found to be between $7.86 \mathrm{eV}^{23} \mathrm{p} .11$, and $8.1 \mathrm{eV}{ }^{36}$.)

Because of the low vibrational temperature, the decomposition of $C N$ in the gas phase can proceed only by reaction such as*

$$
C N_{g}+N_{g} \rightarrow N_{2, g}+C_{g}(\Delta H=-47 \mathrm{kcal} / \mathrm{mole}) .
$$

Using the value of $4 \cdot 10^{13} \mathrm{~cm}^{3}$ mole ${ }^{-1}$ for the reaction rate at a temperature of about $8000^{\circ} \mathrm{K}^{37}$ and an activation energy of about $25 \mathrm{kcal} /$ mole (lower limit), a mean life time of more than $10^{-2}$ sec can be expected for $C N$ in the above reaction. The decomposition may be faster at the wall of the discharge tube at high temperature $\left({ }^{23}, \mathrm{pp} .65\right.$ to 66) as well as by ion-molecule reactions in the gas phase (homogeneous condensation). These estimations lead to the conclusion that $C N$ is a stable species in the gas phase under plasma conditions and its decomposition by electrons is slower than its formation on the wall. This is in agreement with our observation that only paracyanogen was deposited on the wall in the discharge zone at temperatures lower than $800^{\circ} \mathrm{C}$ (see exp. No. IV). No decomposition to the elements, but only polymerization was observed also by other authors in the low-

* The dissociative deexcitation $C N_{g}+X_{g}{ }^{*} \rightarrow C_{g}+N_{g}+X_{g}$ has been discussed in 38 .

35 W. JACKson and J. FARIS, J. chem. Physics 56 (1972) 95.

36 B. Darwent, Bond Dissociation Energies in Simple Molecules, US Nat. Bur. Stand., NSRDS NBS 31 (1970).

37 M. Slack and E. Fishburne, J. chem. Physics 56 (1972) 95.

38 S. Vepřek, H. R. Oswald and W. Peier, Z. angew. Math. Physik [Basel] 23 (1973) 1006. 
pressure discharge in cyanogen $(C N)_{2}\left({ }^{23}\right.$, p. 67$)$. The polymerization of $C N$ to $(C N)_{x}$ occurs in the gas phase and can be accelerated by ions ( ${ }^{23}, \mathrm{pp} .22$ and 67$)$. The reverse reaction $(C N)_{2, g} \rightarrow 2 C N_{g}$ has a high activation energy of $95-125 \mathrm{kcal} / \mathrm{mole}\left({ }^{23}, \mathrm{p} .5\right)$ and may be omitted here.

From the point of view of the above discussion the transport of carbon in nitrogen plasma proceeds by the following steps:

$$
\begin{array}{lll}
C_{s}+N_{g} \frac{\varepsilon_{2}}{T_{2}>1000^{\circ} \mathrm{K}} \rightarrow C N_{g} & \frac{\varepsilon_{1}}{T_{1}<800^{\circ} \mathrm{K}} \rightarrow & (C N)_{x, s} \\
\varepsilon_{2}>\varepsilon_{1} & \frac{\varepsilon_{1}}{T_{1}>1200^{\circ} \mathrm{K}} \rightarrow C_{s}+\frac{1}{2} N_{2, g}
\end{array}
$$

$T$ is the translational temperature and $\varepsilon$ the plasma energy. The reaction

$$
\begin{aligned}
C_{s}+N\left({ }^{4} S\right) & \rightleftharpoons C N\left(X^{2} \Sigma^{+}\right) \\
\Delta H_{298}^{\circ} & =-4 \mathrm{kcal} / \mathrm{mole}
\end{aligned}
$$

is weakly exothermic and the chemical equilibrium is shifted to the right ( $\log K_{p} \approx 3$ at $1300^{\circ} \mathrm{K}^{22}$ ), but its setting up requires a high temperature of solid carbon in zone 2.

This is illustrated by a comparison of the amount of carbon transported at different translational temperatures with theoretical predictions (see ${ }^{4}$, Table 1 ). If the temperature is too low (e.g. $890^{\circ} \mathrm{K}$ ), the formation of $C N$ on the graphite surface according to eq. (5) proceeds slowly, whereas at a higher temperature (e.g. $1275^{\circ} \mathrm{K}$ ) it is fast. The theoretical considerations ${ }^{4}$ are based on the assumption, that the chemical reactions under plasma conditions are faster than other processes of energy dissipations. One can see from the comparison mentioned above, that the theoretical predictions and the experiments agree better at higher translational temperature. This is an important limitation of applicability of the statistical model ${ }^{4}$ as well as the method of simple energy diagrams ${ }^{2}$, and it is a subject of our further paper ${ }^{38}$.

\section{Conclusions}

Transport of carbon takes place in a nonisothermal nitrogen plasma along a gradient of decreasing plasma energy when the degree of dissociation and the translational temperature reach high values in the "starting zone". The discussion of elementary processes shows that the formation of gaseous $C N$ radicals occurs by the reaction of 
nitrogen atoms with solid carbon. The translational temperature of the plasma plays an important kinetic role in this reaction.

We have shown in an earlier paper ${ }^{2}$ how it is possible to predict the direction of chemical transport, as well as the relative amount of plasma energy necessary for chemical transport to take place in a plasma. According to the statistical model ${ }^{4}$, simple energy level-diagrams can be used for this prediction (cf. ${ }^{2}$ ). The exact plasma parameters necessary for chemical transport to take place in a system of interest have to be found experimentally.

According to our opinion, this procedure can be a relatively favourable approach in planning further experiments for crystal growth and preparation of thin films by the use of a nonisothermal low-pressure plasma.

\section{Acknowledgment}

The experimental part of this work has been done by the author at the Institute of Inorganic Chemistry, the University of Münster. The author is indebted to Professor H. SchäFER for standing support during this work and many valuable discussions and advices. He thanks also to Professor H. R. Oswald for his helpful remarks in the theoretical part of this work. 